\title{
A novel laparoscopic technique for drainage of hydatid cyst in posterior segment of liver
}

\author{
Manash Ranjan Sahoo, Anil Kumar T, Manoj Gowda
}

\begin{abstract}
Introduction: Although several surgeries have proven to be effective for hydatid cyst of liver, but laparoscopic surgery has its own stand. We report here a novel laparoscopic technique for drainage of hydatid cyst in posterior segment of liver in a series of four patients who had two hydatid cysts in same lobe of the liver. Case Series: Four patients who presented with right upper abdominal pain was investigated with ultrasound and computed tomography scan which revealed two hydatid cyst in same right lobe of liver with one of the cyst in posterior segment. On the operating table laparoscopically first cyst was drained with Palanivelu's hydatid system and irrigated with chlorexidine solution. Through this first cyst second cyst in the posterior segment was punctured, drained and irrigated. Postoperative period was uneventful. Conclusion: This novel technique of approaching second cyst through first cyst is safe, feasible, very effective for cysts in the posterior segments and yield good results and can also approach a third cyst, if it is near to the first cyst. If there are three or more cysts, we can reduce multiple deroofing by approaching the other nearer cysts through already deroofed cyst.
\end{abstract}

Manash Ranjan Sahoo ${ }^{1}$, Anil Kumar T2 ${ }^{2}$, Manoj Gowda² Affiliations: ${ }^{1} \mathrm{MS}$, Associate Professor, Department of Surgery, S.C.B. Medical College, Cuttack, Odisha, India; ${ }^{2}$ Post Graduate, Department of Surgery, S.C.B. Medical College, Cuttack, Odisha, India

Corresponding Author: Dr. Manash Ranjan Sahoo, Orissa Nursing Home, Medical road, Ranihat, Cuttack, Odisha, India - 753007; Phone: +919937025779; Fax: 06712414034; Email: manash67@gmail.com

Received: 14 November 2012

Accepted: 07 February 2012

Published: 01 April 2013
Keywords: Hydatid cyst, Posterior segment, Palanivelu's hydatid system

$$
* * * * * * * * *
$$

Sahoo MR, Kumar TA, Gowda M. A novel laparoscopic technique for drainage of hydatid cyst in posterior segment of liver. International Journal of Case Reports and Images 2013;4(4):194-198.

$$
* * * * * * * * *
$$

doi:10.5348/ijcri-2013-04-293-CS-2

\section{INTRODUCTION}

Hydatid cyst is a parasitic disease caused by the tapeworm Echinococcus granulosus or Ech. Alveolaris. Hydatid disease is endemic mainly in the Mediterranean countries, the Middle East, South America, India, northern China [1]. However, disease may be encountered worldwide sporadically because of increased travel and immigration $[2,3]$. Hydatid disease is a rare entity primarily affecting the population of developing countries. In human most hydatid cyst occur in the liver and $75 \%$ of these are single cyst. Other common organs included are lung, spleen and kidney [4]. Treatment of echinococcal infestation has a major impact on the health care economy in an endemic region [5]. Operation is the treatment of choice for most individuals infected with Echinococcus granulosus. Use of antihelminthic medications complements surgical management but does not replace it. The conventional operative procedures of the hydatid cyst of the liver are enucleation, cystectomy, evacuation, marsupilisation, etc. It involves a significant morbidity especially in term of wound infection. The World Health Organization (WHO) recommends percutaneous aspiration, irrigation and re-aspiration (the PAIR approach) [6]. Laparoscopic treatment of hepatic hydatid disease has been increasingly popular parallel to the progress in 
laparoscopic surgery [7]. However, fear of anaphylactic shock resulting from spill-age of hydatid fluid during treatment by the minimally invasive method may be discouraging for wider adoption of this technique [8].

We report here a novel laparoscopic technique for drainage of hydatid cyst in posterior segment of liver in a series of four patients who had two hydatid cysts in same lobe of the liver by approaching second cyst in the posterior segment through the first cyst.

\section{CASE SERIES}

Four patients presented to us with a history of right upper quadrant pain with no other significant symptoms. Ultrasound scan revealed two cystic lesions with membranes with spoke wheel appearance which are features of hydatid cyst in the right lobe of liver with one of the cyst in posterior segment of liver. Computed tomography (CT) scan confirmed the diagnosis in all cases. Liver function tests were normal in all patients. There were no features of choangitis or cholestasis. All other biological parameters were normal. All the patients were planned for laparoscopic drainage.

Under general anesthesia through a four-port (two $10 \mathrm{~mm}$, two $5 \mathrm{~mm}$ ports) approach bulge was identified over liver (Figure 1). Cyst was identified by aspirating with veress needle inserted transfascially. Keeping veress needle in place Palanivelu's hydatid system was introduced (Figure 2) and punctured the cyst at the site of insertion of veress needle and cyst content aspirated without spillage. Continuous aspiration was done with irrigation of cyst with cetrimide solution. Then telescope was introduced to visualize the interior of cyst, if any redundant material left, it was irrigated and aspirated, deroofing of the cyst was done after removal of ectocyst membrane (Figure 3) and looked for any biliary leakage which was found in two of our cases which was ligated with figure of eight with 2-O vicryl intracorporeally that prevented further leakage. Now the second cyst which was close to the first cyst but in posterior segment was also aspirated with veress needle to confirm through the drained first cyst. Now the Palanivelu's hydatid system was introduced through the drained first cyst where veress needle is introduced. Again same procedure of aspiration, irrigation with cetrimide and again aspiration was done. Ectocyst membrane of the posterior hydatid cyst was removed through the first cyst (Figure 4). Lastly, interior of both first and second cyst was visualized with telescope for redundant daughter cyst and bile leakage. Abdomen was irrigated with normal saline. Closed tube drain was placed within the cyst cavity and ports closed.

Postoperatively, patients had very good recovery and it was uneventful.

\section{DISCUSSION}

Although liver hydatid cysts are usually asymptomatic, the most common symptoms are pain

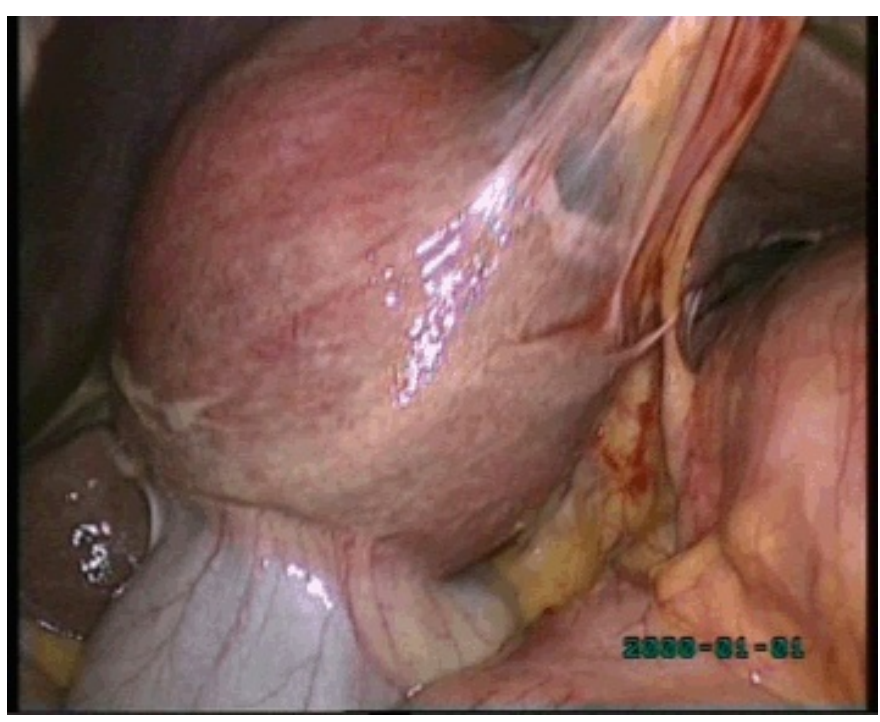

Figure 1: Hydatid cyst on the anterior aspect of liver.

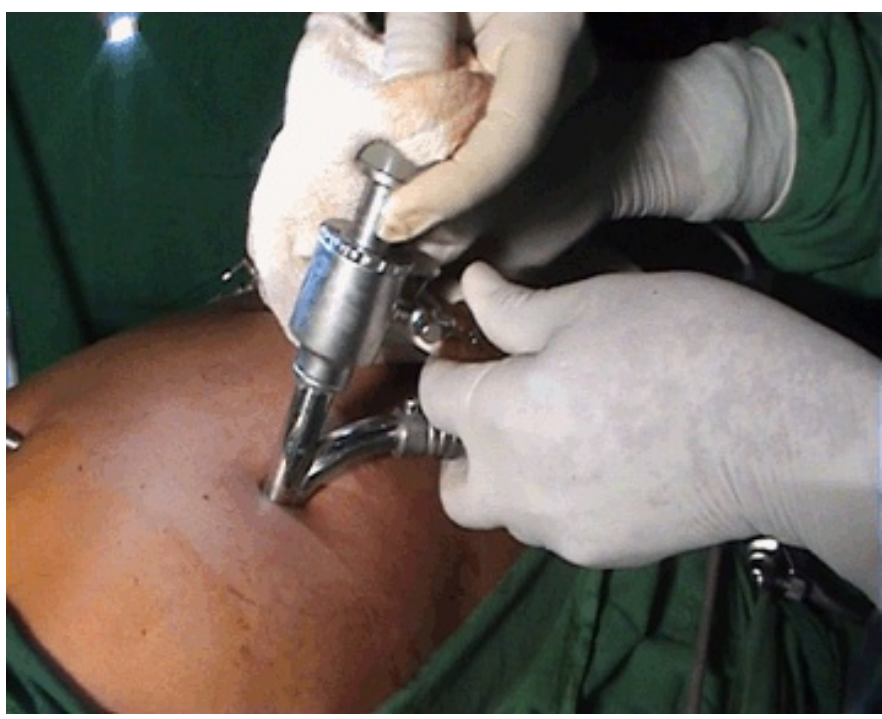

Figure 2: Hydatid cyst aspiration using Palanivelu's hydatid system.

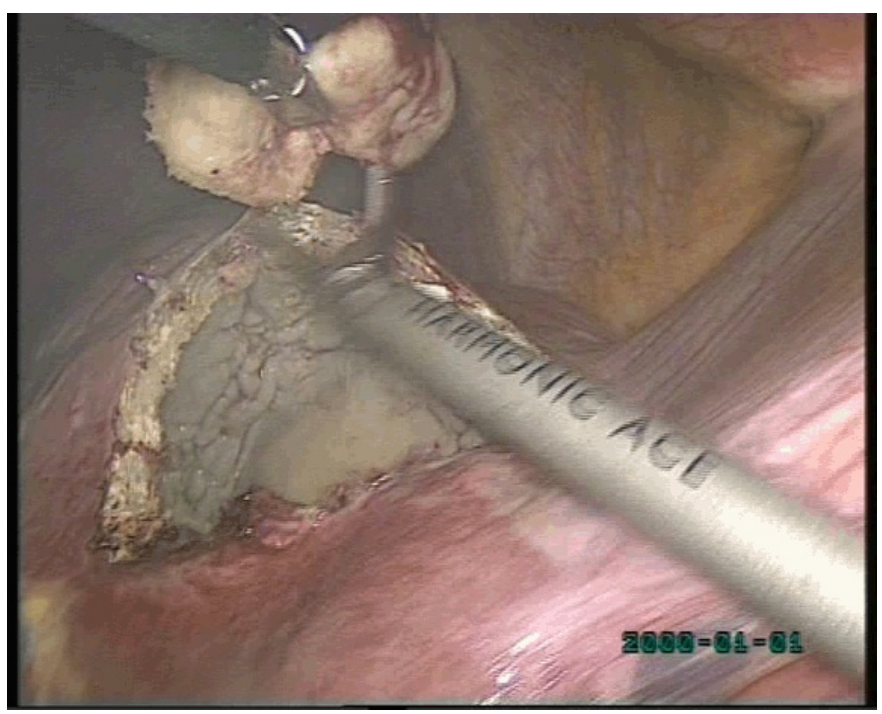

Figure 3: Deroofing of the first cyst after removal of ectocyst. 


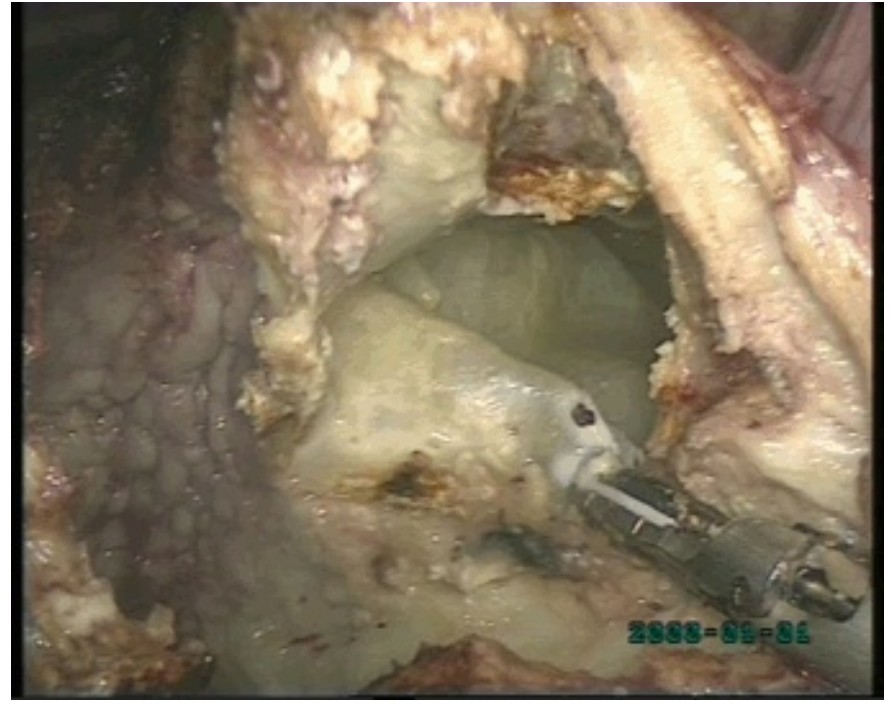

Figure 4: Removal of ectocyst from the posterior hydatid cyst.

and hepatomegaly. Fever and jaundice may accompany complicated cysts. Ultrasonography is the primary diagnostic tool owing to its low cost, and high specificity and sensitivity. Computed tomography, magnetic resonance imaging (MRI) (MRCD) may be used for better documentation and definition of the vascular/biliary anatomy. Ultrasound is particularly useful for the detection of cystic membranes, septa, and hydatid sand, while CT best demonstrates cyst wall calcification and cyst infection [9]. Ultrasonographic appearances have also formed the basis of classification of liver hydatid cysts by various authorities like Gharbi [10], WHO [6], and Milicevic [11].

Treatment depends on stage, localization, size, and complications of the cysts. Chemotherapy should be the first choice for disseminated disease and for patients who have a prohibitively high risk for surgery. Albendazole in the dose of $10-15 \mathrm{mg} / \mathrm{kg} /$ day is used [12] in conditions like widely disseminated hydatid disease [13], localized disease in poor surgical risk patients [14], ruptured cysts [15], and patients in whom significant intraoperative spillage has occurred $[16,17]$. Franchi et al. used $10 \mathrm{mg} / \mathrm{kg} /$ day albendazole on 448 patients with uncomplicated hydatid cyst for 6 months. They found that $74 \%$ of the patients had degeneration in their cysts, and the persistence rate was $25 \%$ at the end of 6 months [18].

Surgery is the primary treatment for echinococcal disease. The appropriate treatment of hydatid cyst is determined by several factors and is surgical or percutaneous drainage with intracystically injected scolicidal agents and chemotherapy. The most common techniques for liver hydatid disease treatment are marsupialization, partial cystopericystectomy with resection of the pericyst and subtotal pericystectomy by peeling the pericystium. Cystectomy is considered the least traumatic method for hydatid cysts excision, but there is typically a larger residual cavity that can lead to a number of life-threatening complications such as suppuration, recurrence, and biliary fistula. Suture obliteration, omentoplasty, introflexion, double breasting, simple closure, deroofing, and tube drainage [19-25] are the most commonly used techniques for residual cavity management. If the cyst is localized peripherally, total cystectomy or hepatic resection is recommended because of the low rate of recurrence.

The first report of laparoscopic treatment of hydatid cyst of the liver was published in 1994 [26] followed soon thereafter by the first report of anaphylactic shock complicating laparoscopic treatment of hydatid cysts of the liver [27]. Laparoscopic treatments that have been described include cystotomy, partial pericystectomy, and total pericystectomy [28, 29]. Laparoscopic techniques are gaining popularity even though no failsafe methodology has been devised to completely ensure the prevention of cyst spillage. Good laparoscopic candidates include those with superficial fluid filled cysts. One of the problems faced in laparoscopic treatment of liver hydatid cysts is the difficulty in evacuating the particulate contents of the cyst, the daughter cysts, and laminated membrane. Various instruments have been described to evacuate the contents of hydatid cysts [30-36]. Advantages of the laparoscopic procedures include less pain, good cosmetic results, rapid recovery, and decreased complications. The only cysts not removed laparoscopically are deep intraparenchymal cysts close to the vena cava, or cysts containing thick, calcified walls $[37,38]$. A study out of Amsterdam demonstrated that laparoscopic treatment of anteriorly located hepatic cysts had a success rate of $77-100 \%$, with low complication and recurrence rates $0-17 \%$ and $1-9 \%$, respectively [39].

In this series, we drained the second cyst of the liver located in the posterior segment through first laparoscopically without any difficulty thereby accessing even the posterior segment hydatid cyst giving patient benefit of minimal invasive surgery.

\section{CONCLUSION}

This novel technique of approaching second cyst through first cyst is safe, feasible, very effective for cysts in the posterior segments and yield good results and recommend this technique in selected patients.

$* * * * * * * * *$

\section{Author Contributions}

Manash Ranjan Sahoo - Conception and design, Acquisition of data, Analysis and interpretation of data, Drafting the article, Final approval of the version to be published

Anil Kumar T - Conception and design, Acquisition of data, Analysis and interpretation of data, Drafting the article, Critical revision of the article, Final approval of the version to be published

Manoj Gowda - Conception and design, Analysis and interpretation of data, Drafting the article, Final approval of the version to be published 


\section{Guarantor}

The corresponding author is the guarantor of submission.

\section{Conflict of Interest}

Authors declare no conflict of interest.

\section{Copyright}

(C) Manash Ranjan Sahoo et al. 2013; This article is distributed under the terms of Creative Commons Attribution 3.0 License which permits unrestricted use, distribution and reproduction in any means provided the original authors and original publisher are properly credited. (Please see www.ijcasereportsandimages.com /copyright-policy.php for more information.)

\section{REFERENCES}

1. Tselentis J, Karpathios T, Fretzayas A, Korkas A, Nicolaidou P, Matsaniotis N. Hydatid disease in asymptomatic young carries in northern Greece. Am J Trop Med Hyg 1983;32(6):1462-3.

2. Huizinga WKJ, Grant CS, Daar AS. Hydatid disease. In: Morris PJ, Wood WC, editors. eds. Oxford Textbook of Surgery. 2nd ed. New York, NY: Oxford University Press 2000:3298-305.

3. Schantz PM, Schwabe C. Worldwide status of hydatid disease control. J Am Vet Med Assoc 1969 Dec 15;155(12):2104-21.

4. Skroubis G, Vagianos C, Polydorou A, Tzoracoleftherakis E, Androulakis J. Significance of Bile Leaks Complicating Conservative Surgery for Liver Hydatidotis. World J Surg 2002 Jun;26(6):704-8.

5. Barnes SA, Lillemoe KD. Zinner MJ, Schwartz SI, Ellis H. Appleton \& Lange; Stamford. Liver abscess and hydatid cyst disease, Maingot's Abdominal Operations1oth edn 1997:1534-45.

6. Brunetti E, Filice C, Macpherson C, et al. PAIR: Puncture, Aspiration, Injection, Re-Aspiration. An option for the treatment of Cystic Echinococcosis. WHO/EMC web site Available at:www.who.int/emcdocuments/zoonoses/whocdscsraph20016.html Accessed on October 15, 2004.

7. Dervenis C, Delis S, Avgerinos C, Madariaga J, Milicevic M. Changing concepts in the management of liver hydatid disease. J Gastrointest Surg 2005 Jul-Aug;9(6):869-77.

8. Yaghan R, Heis H, Bani-Hani $\mathrm{K}$, et al. Is fear of anaphylactic shock discouraging surgeons from more widely adopting percutaneous and laparoscopic techniques in the treatment of liver hydatid cyst? Am J Surg 2004;187(4):533-7.

9. Pedrosa I, Saíz A, Arrazola J, Ferreirós J, Pedrosa CS. Hydatid disease: radiologic and pathologic features and complications. Radiographics 2000;20(3):795-817.

10. Gharbi HA, Hassine W, Brauner MW, Dupuch K. Ultrasound examination of the hydatid liver. Radiology 1981 May;139(2):459-63.

11. Milicevic MN. Hydatid disease. In: Blumgart LH, Fong Y, editors. eds. Surgery of the Liver and Biliary
Tract. 3rd ed. Philadelphia, PA: WB Saunders Company Ltd 2002:1167-204.

12. Kern P. Echinococcus granulosus infection: clinical presentation, medical treatment and outcome. Langenbecks Arch Surg 2003 Dec;388(6):413-20.

13. Schantz PM, Schwabe C. Worldwide status of hydatid disease control. J Am Vet Med Assoc 1969 Dec 15;155(12):2104-21.

14. King CH. Cestodes (tapeworms). In: Mandell GL, Bennett JE, Dolin R, editors. Principles and Practice of Infectious Diseases. 4th ed. New York, NY: Churchill Livingstone 1995:2544-553.

15. Gómez R, Marcello M, Moreno E, et al. [Incidence and surgical treatment of extrahepatic abdominal hydatidosis]. Rev Esp Enferm Dig 1992 Aug;82(2):100-3.

16. Beecherl EE, Bigam DL, Langer B, et al. Cystic diseases of the liver. In: Zuidema GD, Yeo CJ, editors. eds. Shackelford's Surgery of the Alimentary Tract. 5th ed. Vol III, Philadelphia, PA: WB Saunders Company 2000:452-60.

17. Milicevic MN. Hydatid disease. In: Blumgart LH, Fong Y, editors. eds. Surgery of the Liver and Biliary Tract. 3rd ed. Philadelphia, PA: WB Saunders Company Ltd 2002:1167-204.

18. Franchi C, Di Vico B, Teggi A. Long-term evaluation of patients with hydatidosis treated with benzimidazole carbamates. Clin Infect Dis 1999;29(2):304-9.

19. Sayek I, Onat D, Diagnosis and treatment of uncomplicated hydatid cyst of the liver. World Journal of Surgery 2001;25(1):21-7.

20. Köksal N, Müftüoglu T, Günerhan Y, Uzun MA, Kurt R. Management of intrabiliary ruptured hydatid disease of the liver. HepatoGastroenterology 2001;48(40):1094-6.

21. Kayaalp C, Sengul N, Akoglu M. Importance of cyst content in hydatid liver surgery. Archives of Surgery 2002;137(2):159-63.

22. Sreevathsa MR, John AK. Double breasting technique for residual cavity in hepatic hydatid. Journal of the Royal College of Surgeons of Edinburgh 1997;42(4):244-5.

23. Safioleas M, Misiakos EP, Kakisis J, et al. Surgical treatment of human echinococcosis. International Surgery 2000;85(4):358-65.

24. Vagianos CE, Karavias DD, Kakkos SK, Vagenas CA, Androulakis JA. Conservative surgery in the treatment of hepatic hydatidosis. Eur $J$ Surg 1995;161(6):415-20.

25. Kama NA, Sahin M, Göçmen E, Bayrak M, Kulaçoglu $\mathrm{H}$, Akat AZ. The results of surgical techniques in hepatic hydatidosis: treatment with drainage versus treatment without drainage-a 6-year experience. Journal of the Royal College of Surgeons of Edinburgh 1998;43(4):254-56.

26. Bickel A, Loberant N, Shtamler B. Laparoscopic treatment of hydatid cyst of the liver: initial experience with a small series of patients. J Laparoendosc Surg 1994;4(2):127-33.

27. Khoury G, Jabbour-Khoury S, Soueidi A, Nabbout G, Baraka A. Anaphylactic shock complicating laparoscopic treatment of hydatid cysts of the liver. Surg Endosc 1998;12(5):452-4.

28. Ramachandran CS, Goel D, Arora V. Laparoscopic surgery in hepatic hydatid cysts: a technical improvement. Surg Laparosc Endosc Percutan Tech 2001 Feb;11(1):14-8. 
29. Dervenis C, Delis S, Avgerinos C, Madariaga J, Milicevic M. Changing concepts in the management of liver hydatid disease. Journal of Gastrointestinal Surgery 2005;9(6):869-77.

30. Bickel A, Eitan A. The use of a large transparent cannula, with a beveled tip, for safe laparoscopic management of hydatid cysts of liver. Surg Endosc 1995 Dec;9(12):1304-5.

31. Bickel A, Loberant N, Singer-Jordan J, Goldfeld M, Daud G, Eitan A. The laparoscopic approach to abdominal hydatid cysts: a prospective nonselective study using the isolated hypobaric technique. Arch Surg 2001;136(7):789-95.

32. Saglam A. Laparoscopic treatment of liver hydatid cysts. Surg Laparosc Endosc 1996;6(1):16-21.

33. Alper A, Emre A, Hazar H, et al. Laparoscopic surgery of hepatic hydatid disease: initial results and early follow-up of 16 patients. World J Surg 1995;19(5):725-8.

34. Kayaalp C. Evacuation of hydatid liver cysts using laparoscopic trocar. World J Surg 2002;26(11):1324-7.
35. Al-Shareef Z, Hamour OA, Al-Shlash S, Ahmed I, Mohamed AA. Laparoscopic treatment of hepatic hydatid cysts with a liposuction device. JSLS 2002;6(4):327-30.

36. Zengin K, Unal E, Karabicak I, Apaydin B, Taskin M. A new instrument, the "Perfore-Aspirator" for laparoscopic treatment of hydatid cysts of the liver. Surg Laparose Endosc Percutan Tech 2003;13(2):80-2.

37. Ertem M, Uras C, Karahasanoglu T, Erguney S, Alemdaroglu K. Laparoscopic approach to hepatic hydatid disease. Digestive Surgery 1998;15(4):333-6.

38. Luján Mompeán JA, Parrilla Paricio P, Robles Campos R, García Ayllón J. Laparoscopic treatment of a liver hydated cyst. British Journal of Surgery 1993;80(7):907-8.

39. Schipper HG, Kager PA. Diagnosis and treatment of hepatic echinococcosis: an overview. Scand J Gastroenterol Suppl 2004;(241):50-5.
Access full text article on other devices

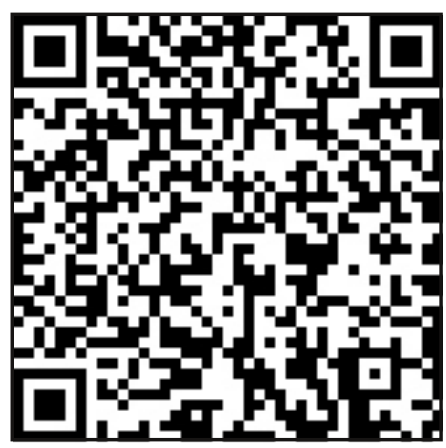

Access PDF of article on other devices

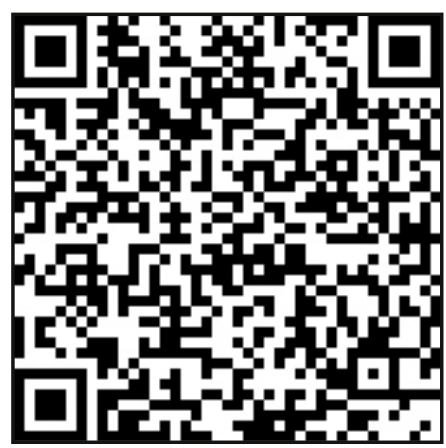

